\title{
Bacterial and Parasitic Profile of Acute Infectious Pediatric Diarrhoea and the Role of Faecal Screening Tests in Prediction of The Invasive Type of Diarrhoea
}

\author{
Hadir Mahmoud El Kady*, Soryia Aly El-Shazly*, Abeer Aly Omar*, Amal Abd El Fattah El
}

Sahn**, Ahmed Abd El Salam Madkour***

\begin{abstract}
Diarrhoea is one of the leading causes of morbidity and mortality in children worldwide. Faecal screening methods as detection of faecal leucocytes, faecal lactoferrin and faecal occult blood, have diagnostic and therapeutic implications in the provisional diagnosis of invasive diarrhea before culture results made available. Aim of the work was to outline the bacterial and parasitic profile of acute pediatric diarrhoea and to evaluate faecal screening tests in preliminary diagnosis of invasive diarrhoea. Three hundred children under five years of age, suffering from acute diarrhoea ( $<4$ days) and attending the out-patient clinic of El Shatby Children's University Hospital in Alexandria, over a period of 1 year, were recruited in the study. Stool samples were collected from the children and were subjected to bacteriological examination, parasitological examination and 3 faecal screening tests to distinguish invasive (inflammatory) from non invasive (non inflammatory) diarrhoea. Forty eight percent of samples were positive for enteric pathogens. Enteric bacterial pathogens were isolated from $25 \%$ of samples. Parasites $29 \%$ and mixed bacterial and parasitic infections were detected in $6 \%$ of samples. Enterotoxigenic E.coli (ETEC) was the most common bacterial isolate detected in $10 \%$ of samples, followed by Salmonella (8\%), Shigella $(6.67 \%)$ Campylobacter (5\%) and Vibrio parahaemolyticus (1.33\%). Cryptosporidium was the most commonly identified parasite (13\%) followed by Giardi lamblia (11\%), Entamoeba histolytica (8\%) and Cyclospora cayetanensis (3\%). Ascaris lumbricoides and Haeminolipus nana were only identified in $1 \%$ of samples, each. The gold standard for evaluation of faecal screening tests was positive culture for invasive bacterial pathogens and/or positive E. histolytica on microscopic examination of stool samples. Leuko test had the highest sensitivity $(85.54 \%)$, specificity $(73.73 \%)$, positive predictive value $(55.47 \%)$, negative predictive value $(93.02 \%)$ and accuracy $(77 \%)$. False positive results of the Leuko-test were significantly higher in the breast-fed children than non breast-fed ones $(26.7 \%$, $11.7 \%$ respectively, $p<0.01$ ). Better sensitivity, specificity, positive and negative predictive values of the Leuko-test was recorded in the non breast-fed children than in the breast-fed ones. The recorded values in the first group were: $91.11 \% .83 .64 \%, 69.5 \%$ and $95.83 \%$, respectively compared to $78.95 \%, 63.55 \%, 43.48 \%$ and $89.47 \%$, respectively in the second group. The study concluded that, Leuko test is the best applicable faecal screening test in differentiation of invasive and non invasive diarrhoea but is better avoided in breast-fed infants as many false positive results might be interpreted.
\end{abstract}

\footnotetext{
* Department of Microbiology, High Institute of Public Health, Alexandria University

** Department of Tropical Health, High Institute of Public Health, Alexandria University

*** Department of Pediatrics, Faculty of Medicine, Alexandria University.
} 


\section{INTRODUCTION:}

Diarrhoea is defined as the passage of three or more loose or watery stools per day or a single loose stool containing blood, pus or mucus (invasive diarrhoea)..$^{(1,2)}$

Diarrhoea is still one of the leading causes of morbidity and mortality in children worldwide, causing one billion episodes of illness and 3-5 million deaths annually. ${ }^{(3)}$. The incidence of diarrhoeal episodes in developing countries ranges from 2-5 illnesses per year. ${ }^{(4)}$. In Egypt it was estimated that 10 million Egyptian children, under five, suffer 30 million episodes of diarrhoea annually and that diarrhoea is responsible for about $14.64 \%$ of deaths in this age group and is the leading cause of malnutrition ;impairing the quality of life of Egyptian children.(5,6)

The main bacterial causative agents of pediatric diarrhoea include: Shigella, Salmonella, Campylobacter, E. coli and vibrios. ${ }^{(7,8)}$ Notable parasitic infections include those of Giardia lamblia, Entamoeba histolytica and Cryptosporidium.(9)

Unlike most diarrhoeal illnesses which are self-limited, invasive diarrhoea necessitates extensive diagnostic studies and specific antimicrobial therapy to shorten the clinical course, decrease excretion of multiresistant organisms or to prevent complications. ${ }^{(3,10,11)}$.

Stool culture is the standard method for diagnosis, however it is tedious, laborious and time consuming. Faecal screening methods (as detection of faecal leuocytes, faecal lactoferrin and faecal occult blood), have diagnostic and therapeutic implications in the provisional diagnosis of invasive diarrhea, as they are rapid and simple to perform. ${ }^{(2,12)}$

Examination of methylene blue-stained smears is the traditional method for detection of leucocytes in stool samples. ${ }^{(13)}$ To be interpreted as positive; $\geq 5$ leucocytes HPF must be identified in the majority of fields or $>10$ leucocytes in a 
single field should be detected. ${ }^{(14)}$

Test for occult blood in stool depends on the oxidative capacity of hemoglobin. ${ }^{(10,15)}$ HEMA SCREEN ${ }^{\mathrm{TM}}$ slide is an electrophoresis paper impregnated with natural guaiac resin. When occult blood is present in stool, its hemoglobin portion incorporated in the slide comes in contact with guaiac incorporated in the slide. On addition of HEMA SCREEN ${ }^{\mathrm{TM}}$ peroxide developing solution, a guaiacperoxidase like reaction occurs. The chemical reaction is visualized by the appearance of a blue-green colour within 30 seconds- 2 minutes. ${ }^{(15)}$

Leuko test is a semiquantitative method for detection of faecal leucocytes using an anti lactoferrin latex bead agglutination assay. When lactoferrin is present in elevated levels in stool sample, it cross links the anti-lactoferrin antibody coated latex beads giving visible agglutination. Latex beads coated with normal IgG serves as a negative control to identify non specific reactions. ${ }^{(16)}$

\section{Aim of the study:}

1. To outline the bacterial and parasitic profile of acute pediatric diarrhoea.

2. To evaluate three faecal screening tests in preliminary diagnosis of invasive diarrhoea.

\section{SUBJECTS AND METHODS:}

The present study involved 300 infants and children, under five years of age, suffering from acute diarrhoea ( $<4$ days) and attending the out-patient clinic of El Shatby Children's University Hospital in Alexandria, over a period of one year. All cases didn't receive any antibiotic therapy at least within the 48 hours prior to sampling.

Stool samples were collected from the children in sterile containers and were subjected to bacteriological examination, parasitological examination and 3 faecal screening tests to distinguish invasive (inflammatory) from non invasive (non inflammatory) diarrhoea. 


\section{Bacteriological examination:}

Each sample was directly cultured on the surface of Mac Conkey agar, xylose lysine deoxycholate (XLD) agar, thiosulphate citrate bile salt (TCBS) agar, sorbitol Mac Conkey (SMAC) agar, Salmonella shigella (SS) agar and Modified Skirrow's agar. All samples were also inoculated on selenite broth, Gram negative (GN) broth and alkaline peptone water (APW) for primary enrichment of Salmonella, Shigella and vibrios; respectively. The tubes were incubated and were then subcultured on XLD and SS agar for the first two and on TCBS agar for the third. Media were incubated according to standard methods and isolated colonies were identified according to the methods described by Bailey and Scott's.(17) Suspected enterobactericae were confirmed using API 20E (BIO Merieux sa 008040-06/00).(18) Diarrhoeagenic E.coli were identified using Ecoli $O 157$ latex test
(Oxoid DR $620 \mathrm{M}$ ) (19) and GM1-ELISA for detection of enterotoxigenic E.coli.(20)

\section{Parasitological examination:}

Each stool sample was subjected to direct microscopic examination for identification of motile trophozoites, formol ether concentration for detection of protozoan cysts and helminthic ova and larvae and modified Ziehl-Neelsen stain for detection of Cryptosporidium and Cyclospora oocysts. (21)

\section{Faecal screening tests:}

\section{Direct microscopic examination:}

Faecal smears were thoroughly mixed with 2 drops of methylene blue on glass slides. A cover-slide was placed on the stained suspension and 2-3 minutes were allowed for good nuclear staining of leucocytes. The test was considered positive if $\geq 5$ leucocytes were detected in the majority of 20 fields or $>10$ leucocytes were detected in 1 field; examined by the 40X objective lens. ${ }^{(22,23-24)}$ 
II. Detection of occult blood in stool using HEMA SCREEN ${ }^{\mathrm{TM}}$ test:

A very thin portion or several drops of a faecal suspension were applied inside the oval locations indicated with Roman numeral I and II on the HEMA SCREEN ${ }^{\mathrm{TM}}$ test slide. Through the perforated section on the back of the slide, a drop of HEMA SCREEN ${ }^{\mathrm{TM}}$ developing solution (stabilized mixture of hydrogen peroxide $<6 \%$ and $75 \%$ denatured ethyl alcohol in aqueous solution) was added directly on the control area between positive and negative performance standards. Two or more drops of the developer were applied to oval I and II. Any trace of blue colour within 2 minutes was considered as a positive result indicating presence of occult blood in sample. ${ }^{(15)}$

\section{Detection of faecal lactoferrin using}

\section{Leuko- Test:}

Fifty $\mu$ of the tested stool sample were diluted 1:50 and thoroughly mixed using a vortex mixer. For each sample, two circles on the agglutination card were used: one for testing the sample itself and the other used as a negative control. A positive control was done for each group of tested samples. A drop of sensitized latex was placed on each tested sample and on the positive control reagent. A drop of negative control latex was tested with a drop of the diluted sample simultaneously. Cards were rotated gently for 3 minutes. Both the positive control and positive samples showed easily visible agglutination with a clearing background. The negative control and the negative samples showed no visible agglutination. $(25,26)$

The collected data was statistically analyzed and a number of correlations were found. (27)

\section{RESULTS:}

The present study included 300 children (180 females and 120 males) $\leq 5$ years of age with a mean age of 1.98 years. All cases suffered from acute diarhoea $(<4$ days). 
Out of the 300 examined samples; only 144 (48\%) were positive for enteric pathogens. Enteric bacterial pathogens were isolated from 75 samples (25\%) of all samples. Parasites were identified in 87 samples (29\%). Mixed bacterial and parasitic infections were detected in 18 samples (6\%). (Table I)

Diarrhoegenic E.coli strains were the most common bacterial isolates detected in 30 samples (10\%): [27 enterotoxigenic E.coli (ETEC) and 3 E.coli 0157 strains].This was followed by 24 Salmonella spp (8\%): [3 S.typhi, 15 S. enteritidis and 6 S.typhimurium], 20 Shigella spp (6.67\%): [15 S.flexneri and 5 S.dysenteriae], 15 Campylobacter spp (5\%): $[9$ C.jejuni and 6 C.coll $]$ and 4 V.parahaemolyticus isolates (1.33\%). Cryptosporidium was the most commonly identified parasite (13\%) followed by Giardia lamblia 33 (11\%), E.histolytica 24 (8\%) and Cyclospora cayetanensis 9 (3\%). Ascaris lumbricoides and H.nana were only identified in 3samples (1\%), each.(Table II)

The gold standard for evaluation of faecal screening tests was positive culture for invasive bacterial pathogens and/or positive E. histolytica on microscopic examination of stool samples. The 3 samples positive for E.coli 0157 were negative for the 3 faecal screening tests.

Leuko test had the highest sensitivity (85.54\%), specificity (73.73\%), positive predictive value (55.47\%), negative predictive value (93.02\%) and accuracy (77\%). (Table III)

Leuko test was positive in 18 samples positive for Shigella (90\%), 21 samples positive for E. histolytica (87.5\%), 13 samples positive for Campylobacter (86.67\%) and 19 samples positive for Salmonella (79.17\%). (Table IV)

The observed agreement between the results of the faecal leucocytic count and both of occult blood and Leuko-tests was good (68\% and $62 \%$ respectively) and this 
was statistically significant $(p=0.00)($ TableV)

False positive results of the Leuko-test

were recorded in 39 of the breast-fed children $(26.71 \%)$ compared to only 18 of the non breast-fed ones (11.69\%). The difference between both groups was statistically significant $(p<0.01)$. On the other hand, false negative results were recorded in 8 of the breast-fed children $(5.48 \%)$ and in 4 of the non breast-fed ones $(2.6 \%)$. The difference between both groups was not statistically significant (p>0.05). (Table VI)

Better sensitivity, specificity, positive and negative predictive values of the Leuko-test was recorded in the non breastfed children than in the breast-fed ones. The recorded values in the first group were: $91.11 \% .83 .64 \%, 69.5 \%$ and $95.83 \%$, respectively compared to $78.95 \%, 63.55 \%$, $43.48 \%$ and $89.47 \%$, respectively in the second group. (Table VI)

Table 1: Distribution of the enteric pathogens identified in stool culture and parasitological examination of the $\mathbf{3 0 0}$ stool samples.

\begin{tabular}{||c|c|c||}
\hline \multirow{2}{*}{ Identified enteric pathogens } & \multicolumn{2}{|c|}{ Frequency of identification } \\
\cline { 2 - 3 } & $\mathbf{N}^{\circ}$ & $\%$ \\
\hline $\begin{array}{c}\text { Bacterial isolates: } \\
\text { - Single pathogen }\end{array}$ & 39 & 13.00 \\
Polymicrebial & 18 & 6.00 \\
\hline$\quad$ Subtotal & 57 & 19.00 \\
\hline $\begin{array}{c}\text { Identified parasites: } \\
\text { Single species }\end{array}$ Multiple parasites & 45 & 15.00 \\
\hline$\quad$ Subtotal & 24 & 8.00 \\
\hline $\begin{array}{c}\text { Mixed infection } \\
\text { (bacteria\& parasites) }\end{array}$ & 69 & 23.00 \\
\hline
\end{tabular}

NB: Total number of positive stool cultures $=57+18=75(25 \%)$

Total number of samples positive for intestinal parasites $=69+18=87(29 \%)$

Total number of samples with polymicrobial profile $=18+24+18=60(20 \%)$ 
Table 2: Frequency distribution of the different types of enteric pathogens recovered from the $\mathbf{3 0 0}$ stool samples.

\begin{tabular}{|c|c|c|}
\hline \multirow{2}{*}{ Enteric pathogens } & \multicolumn{2}{|c|}{ Frequency of identification } \\
\hline & No & $\%$ \\
\hline \multicolumn{3}{|l|}{ Bacteria: } \\
\hline Diarrhoeagenic E.coli: & 30 & 10 \\
\hline ETEC & 27 & 9 \\
\hline E.coli 0157 & 3 & 1 \\
\hline Salmonella spp : & 24 & 8 \\
\hline S.typhi & 3 & 1 \\
\hline S.enteritidis & 15 & 5 \\
\hline S.typhimurium & 6 & 2 \\
\hline Shigella spp: & 20 & 6.67 \\
\hline S.flexneri & 15 & 5 \\
\hline S.dysenteriae & 5 & 1.67 \\
\hline Campylobacter spp: & 15 & 5 \\
\hline C.jejuni & 9 & 3 \\
\hline C.coli & 6 & 2 \\
\hline V.parahaemolyticus: & 4 & 1.33 \\
\hline \multicolumn{3}{|l|}{ Parasites: } \\
\hline G.lamblia & 33 & 11 \\
\hline E.histolytica & 24 & 8 \\
\hline Cryptosporidium & 39 & 13 \\
\hline C.cayetanensis & 9 & 3 \\
\hline A.lumbricoides & 3 & 1 \\
\hline H.nana & 3 & 1 \\
\hline
\end{tabular}


Table 3: Comparative evaluation of three faecal screening tests in the preliminary diagnosis of invasive diarrhoea.

\begin{tabular}{||l|c|c|c|c|c|}
\hline \multicolumn{1}{|c|}{ Faecal screening test } & $\begin{array}{c}\text { Sensitivity } \\
\%\end{array}$ & $\begin{array}{c}\text { Specificity } \\
\%\end{array}$ & $\begin{array}{c}\text { Positive } \\
\text { predictive } \\
\text { value } \\
\%\end{array}$ & $\begin{array}{c}\text { Negative } \\
\text { predictive } \\
\text { value } \\
\%\end{array}$ & $\begin{array}{c}\text { Accuracy } \\
\%\end{array}$ \\
\hline - Faecal leucocytes & 74.70 & 70.50 & 49.20 & 87.93 & 71.67 \\
\hline - Occult blood test & 73.50 & 71.89 & 50.00 & 71.89 & 72.33 \\
\hline - Leuko test & 85.54 & 73.73 & 55.47 & 93.02 & 77.00 \\
\hline
\end{tabular}

N.B: The gold standard for evaluation of faecal screening tests was positive culture for invasive bacterial pathogens (Salmonella, Shigella, and Campylobacter) and/ or positive E. histolytica in microscopic examination of stool samples.

Table 4: Relationship between the positive results of the three faecal screening tests and the identification of invasive enteric pathogens.

\begin{tabular}{||l|c|c|c|c|c|c||}
\hline \multirow{2}{*}{$\begin{array}{c}\text { Positive result } \\
\text { Invasive }\end{array}$} & \multicolumn{2}{|c|}{$\begin{array}{c}\text { Faecal leucocytic } \\
\text { count }\end{array}$} & \multicolumn{2}{c|}{ Occult blood test } & \multicolumn{2}{c|}{ Leuko test } \\
\cline { 2 - 7 } & No. & $\%$ & No. & $\%$ & No. & $\%$ \\
\hline Salmonella spp(n=24) & 17 & 70.83 & 14 & 58.33 & 19 & 79.17 \\
\hline Shigella spp $(\mathbf{n = 2 0 )}$ & 15 & 75.00 & 16 & 80.00 & 18 & 90.00 \\
\hline Campylobacter $\mathbf{s p p}(\mathbf{n = 1 5 )}$ & 10 & 66.67 & 11 & 73.33 & 13 & 86.67 \\
\hline E. histolytica $(\mathbf{n}=\mathbf{2 4})$ & 20 & 83.33 & 20 & 83.33 & 21 & 87.50 \\
\hline
\end{tabular}

NB: The 3 samples positive for E.coli O:157 were negative for the three faecal screening tests 
Table 5: Agreement between the results of the faecal leucocytic count and both occult blood test and Leuko-test.

\begin{tabular}{|l|c|c|c|c|}
\hline \multirow{2}{*}{ Faecal leucocytes } & \multicolumn{2}{|c|}{ Occult blood test } & \multicolumn{2}{|c|}{ Leuko test } \\
\cline { 2 - 5 } & Positive & Negative & Positive & Negative \\
\hline - Positive & 76 & 50 & 70 & 56 \\
\hline - Negative & 46 & 128 & 58 & 116 \\
\hline - Observed agreement & & 0.68 & \multicolumn{2}{|c|}{0.62} \\
- Kappa coefficient & & 0.34 & \multicolumn{2}{|c|}{0.22} \\
- Z of Kappa & & $5.90^{*}$ & \multicolumn{2}{|c|}{$3.84^{*}$} \\
\cline { 3 - 5 } & p value & 0.000 & \multicolumn{2}{|c|}{0.000} \\
\hline
\end{tabular}

* Significant

Table 6: Effect of breast-feeding on the results of the Leuko-test.

\begin{tabular}{|c|c|c|c|c|}
\hline \multirow{2}{*}{ Leuko-test results } & \multicolumn{2}{|c|}{$\begin{array}{c}\text { Breast-fed } \\
(n=146)\end{array}$} & \multicolumn{2}{|c|}{$\begin{array}{c}\text { Non breast-fed } \\
\quad(n=154)\end{array}$} \\
\hline & No & $\%$ & No & $\%$ \\
\hline - True Positive & 30 & 20.55 & 41 & 26.62 \\
\hline - True Negative & 68 & 46.57 & 92 & 59.74 \\
\hline - False Positive & 39 & 26.71 & 18 & $11.69^{*}$ \\
\hline - False Negative & 8 & 5.48 & 4 & $2.60^{* *}$ \\
\hline - Sensitivity & \multicolumn{2}{|c|}{$78.95 \%$} & \multicolumn{2}{|c|}{$91.11 \%$} \\
\hline - Specificity & \multicolumn{2}{|c|}{$63.55 \%$} & \multicolumn{2}{|c|}{$83.64 \%$} \\
\hline \multirow{2}{*}{$\begin{array}{l}\text { - Positive predictive value } \\
\text { - Negative predictive value }\end{array}$} & \multirow{2}{*}{\multicolumn{2}{|c|}{$\begin{array}{l}43.48 \% \\
89.47 \%\end{array}$}} & \multicolumn{2}{|c|}{$69.50 \%$} \\
\hline & & & \multicolumn{2}{|c|}{$95.83 \%$} \\
\hline
\end{tabular}

N.B: Breast-fed children include both the exclusively breast-fed and those who are supplemented with external diet in addition to breast milk.

${ }^{*} Z=3.350, p<0.01$

${ }^{\star *} Z=1.265, p>0.05$ 


\section{DISCUSSION:}

Diarhoeal diseases continue to be a major global burden. They accounted for $21 \%$ of all deaths in children under five years of age from 1990 to 2000; amounting for 2.5 million deaths. By the year 2005, diarrhoeal diseases accounted for $13 \%$ of all childhood deaths amounting to 1.4 million deaths per year. ${ }^{(28)}$

In the present study enteric pathogens were recovered from $48 \%$ of the studied cases of diarrhoea. In Egypt and worldwide, recovery of enteric pathogens from cases of acute pediatric diarrhoea ranged from $41 \%$ to $64 \%$. (29-35) Failure to identify enteropathogens may be due to clearance of pathogens from the gut at the time of sampling which was only done once in this work, infection with Yersinia enterocolitica and C.difficile which is missed due to lack of suitable culture techniques or diagnostic kits and excluding viral causes of diarrhoea.

Infection with a single enteric pathogen was recorded in $28 \%$ of the studied cases while polymicrobial infection was recorded in $20 \%$ of which. Polymicrobial infection was recorded in similar studies as well. (3638) this is reflection of environmental contamination. In fact, it may be that multiple pathogens act synergistically to produce diarrhoea.

Positive stool culture was recorded in $25 \%$ of examined samples in the current work. Several studies conducted worldwide, reported a positive stool culture that varied widely from $3 \%$ to $64 \%$. $^{(13,31,36,39-}$ 41) Low isolation rates could be attributed to intake of antibiotics, insufficient stool samples provided at time of sampling and performance of stool culture only once.

ETEC was the most common bacterial pathogen isolated in this study from $9 \%$ of samples. Other Egyptian studies reported ETEC as most common enteropathogen, isolated at a rate ranging from $10 \%$ to $27 \% .{ }^{(42-45)}$ Intestinal parasites were detected in $29 \%$ of studied cases. This 
figure is consistent with what was and a negative predictive value ranging previously reported by other from $88 \%$ to $98.5 \%$ were reported in investigators. ${ }^{(46-49)}$.Cryptosporidium was several studies. ${ }^{(12,13,51)}$ isolated in $13 \%$ of cases in this study Evaluation of the occult blood test in .Higher rates of identification were reported in other studies in Egypt in the range of $17 \%$ to $28 \%$. ${ }^{(46-49)}$

Faecal screening tests were used in the current study to predict the presence of invasive pathogens in stool as a step in differentiation of inflammatory and non inflammatory diarrhoea. The faecal leucocytic count showed a sensitivity of $74.7 \%$ which agreed with results of previous studies in which a high sensitivity ranging from $75.5 \%$ to $85 \%$ was recorded. $(24,50,51)$. The recorded specificity of leucocytic count in this study was $70.5 \%$, which coincided with previous reports ranging from $70 \%$ to $88 \% .(50,51,52)$. In the present study, the positive predictive value of this test was $49.2 \%$ and the negative predictive value was $87.93 \%$. A positive predictive value that didn't exceed $60 \%$ the current work, it was found that it had a sensitivity of $73.5 \%$. Previous studies reported a sensitivity ranging from $63 \%$ to $85 \% .(24,51)$ As regards specificity of this test, it was estimated in present investigation as $71.89 \%$. Bardhan et al., (2000), reported a specificity of $68 \%$.(51) The positive and negative predictive values in the present work were $50 \%$ and $71.89 \%$, respectively. In other studies as well, the positive predictive value didn't exceed $55 \%$ while the negative predictive value was sometimes as high as $91 \%$. $^{(50,51)}$

The Leuko test in the current study was proved to have a sensitivity of $85.54 \%$, a specificity of $73.73 \%$, a positive predictive value of $55.47 \%$ and a high negative predictive value of $93.02 \%$. The potential of the Leuko test lies in its high negative predictive value. The absence of faecal 
lactoferrin at a dilution of 1:50 makes the presence of an invasive pathogen unlikely. ${ }^{(12)}$ The recorded accuracy for this test was $77 \%$. The agreement between the results of the Leuko test and the leucocytic count was $62 \%$. In previous studies carried out to evaluate Leuko test, a sensitivity ranging from $62 \%$ to $96.5 \%$, a specificity ranging from $28 \%$ to $90 \%$, a positive predictive value ranging from $11 \%$ to $76 \%$ and a negative predictive value ranging from $71 \%$ to $94 \%$ were recorded. ${ }^{(13,52-54)}$ In agreement with the present findings, previous reports indeed suggested that the Leuko test is considerably more sensitive than the traditionally applied faecal leucocytic count and the occult blood test for diagnosis of inflammatory diarrhoea caused by invasive pathogens. $(11,13,52,55,56)$ In the present study, the Leuko test was positive in $90 \%$ of Shigella positive samples, $87.5 \%$ of E.histolytica positive samples, $86.67 \%$ of Campylobacter positive samples and $79.17 \%$ of
Salmonella positive samples. Several previous studies reported positive results of Leuko test in $85 \%$ to $100 \%$ of stool samples positive for invasive pathogens. ${ }^{11}$, 56) In spite of this, positive results of the Leuko test in enteric infections caused by non invasive pathogens as ETEC were noticed in the present study and in other studies as well. $(13,57)$ False positive results of faecal screening tests in general could be explained by colonic inflammation caused by frequent exposure to infectious bacterial and parasitic agents in endemic areas. Other explanations include: associated non-infectious inflammatory enteritis, presence of invasive pathogens that are sometimes missed on culture or presence of Yersinia enterocolitica, C.difficile or enteroinvasive E.coli for which routine tests are usually not performed. In addition some non invasive pathogens like Rota virus, V.parahaemolyticus and Cryptosporidium may also produce mild inflammation in the intestinal mucosa. 
In the current work it was noticed that the false positive results of the Leuko test were significantly more frequent among breastfed children and better sensitivity, specificity, positive and negative predictive values were recorded among non breast fed children. The false positive results, the limited specificity and negative predictive value of the Leuko test among the breastfed is attributed to the secretion of lactoferrin naturally in breast milk. (58) It was reported that lactoferrin titers ranging from 50-100 $\mathrm{ng} / \mu \mathrm{l}$ could be detected in stool samples of healthy breast-fed infants. ${ }^{(16,58)}$

From the present investigation it could be concluded that:

1. Parasitic agents are responsible for the majority of cases of acute pediatric diarrhoea in Egypt.

2. Diarrhoeagenic E.coli (mainly ETEC) are the most commonly encountered bacterial enteropathogens while
Cryptosporidium is the most common parasite in cases of acute pediatric diarrhoea.

3. Leuko test is the best applicable faecal screening test in differentiation of invasive and non invasive diarrhoea. A negative result rules out the involvement of an invasive pathogen in the diarrhoeal attack.

4. Leuko test is better avoided in breastfed infants as many false positive results may be interpreted.

\section{REFERENCES:}

1. Control and prevention of diarrhoeal diseases in practice. A manual for health workers. 1997;8. NCDDP/ Ministry of health - ARE/ WHO/ EMRO, UNICEF.

2. Sanaka MR, Soffer EE. Acute diarrhoea. The Cleveland clinic 2002. [cited 2003 October] Available from URL:http://www.mdconsult.com.

3. Pickering LK, Synder JD. Gastroenteritis. In: Behrman RE, Kliegman RM, Jenson HB (eds). Nelson textbook of pediatrics. $16^{\text {th }}$ ed. Philadelphia: W.B. Saunders Company 2000; 765-768.

4. Weekly epidemiological record- World Health Organization. The World Health Report 2004. WHO, Geneva.

5. Abd El Salam Y, Okasha M. Study the relation between the prevalence of 
diarrhoea in the rural communities and the hygienic practices of its inhabitants. Alexandria Journal of Pediatrics 1995; 2:219-225.

6. MOHP Unpublished Document.

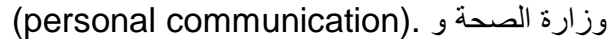

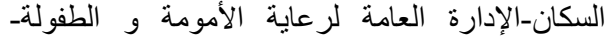
مشروع التخطيط لحصر نسبة و أسباب وفيات الأدة الأطفال إحصاء عام 2005

7. Murray CJ, Hopez AD. Global mortality, disability and the contribution of risk factors: global burden of disease study. Lancet 1997; 349: 1436-42.

8. Claeson M, Merson M. Global progress in the control of diarrhoeal diseases. Pediatr Infect Dis J 1990; 9: 345-55.

9. Hibbs RG. Diarrhoeal disease: Current concepts and future challenges. Introduction. Trans Roy Soc Trop Med Hyg 1993; 87, Suppl 3:1-2.

10. MC Neely WS, Dupont HL. Occult blood versus faecal leucocytes in the diagnosis of bacterial diarrhoea: a study of US travelers to Mexico and Mexican children. Am J Trop Med Hyg 1996; 55(4):430-433.

11. Choi SW, Park ChH, Silva TMJ, Zeanker El, Guerrant RL. To culture or not to culture: Faecal lactoferrin screening assay for inflammatory bacterial diarrhoea. J Clin Microbiol 1996; 34(4):928-32.

12. lactoferrin as a predictor of positive faecal culture in South Indian children with acute diarrhoea. Anals of Tropical Pediatrics 2003; 23:9-13.

13. Silletti RP, Lee G, Ailey E. Role of stool screening tests in diagnosis of inflammatory bacterial enteritis and in selection of specimens likely to yield invasive enteric pathogens. J Clin Microbiol 1996; 34(5):1161-5.

14. Gabriel J, Pelaez R, Mattar S. Accuracy of fecal lacoferrin and other stool tests for diagnosis of invasive diarrhoea at a Colombian pediatric hospital. Pediatr Infect Dis J 1999; 18 (4):342-6.

15. Vogtlin J, Stalder $H$, Hurzeler L. Modified guaiac test may replace search for faecal leucocytes in acute infectious diarrhoea. Lancet 1983; 2:1204.

16. Guerrant $R L$, Araujo $V$, Soares $E$, Kotloff K, Lima AAM, Cooper WH, et al. Measurement of faecal lacoferrin as a marker of fecal leucocytes. J Clin Microbiol 1992; 30(5):1238-42.

17. Forbes BA, Sahm DF, Weissfeld AS. Bailey and Scott's Diagnostic Microbiology. $10^{\text {th }}$ ed. St Louis: Mosby 1998.

18. Smith PB, Tomfohrde KM, Rhoden DL, Balow SA. API system: a multi tube micro method for identification of enterobacteriaceae. Applied Microbiol 1972; 24:449-52.

19. Chapman PA. Evaluation of commercial latex slide test for identifying $\quad E$ coli O157. Infect immune 1989; 42:1109-10.

20. Svnnerholm AM,Wikstrom M, Lindblad M, Holgren J. Monoclonal antibodies against $E$. coli stable toxin (STa) and their use in diagnostic ST ganglioside GM-1 enzyme linked immunosorbent assay. J Clin Micobiol 1986; 24:585-90.

21. Chessbrough M. Intestinal parasites, a major factor in malnutrition. Medicine and the Community 1995; 4 : 16-18.

22. Seva-Pereira A, Franco AO, de Magalhaes AF. Diagnostic value of faecal leucocytes in chronic bowel disease. Revista Paulista Med 1994; 112:504-6.

23. Vandepitte J, Engback K, Piot $\mathrm{P}$, Heuck CC, eds. Basic laboratory procedures in clinical bacteriology. 
Geneva: WHO 1991.

24. Paccagnini S, Ceriani R, Galli L, Principi N, Fontana M, Zuin G, et al. occult blood and faecal leucocyte tests in acute infectious diarrhoea in children. Lancet 1997; 2:442-444.

25. Miller JR, Barrett LJ, Kotloff K, et al. A Rapid test for infectious and inflammatory enteritis. Arch intern med 1994; 154: 2660-4.

26. Fine KD, Ogunji F, George J. Utility of a rapid faecal latex agglutination test detecting the neutrophil protein, lactoferrin, for diagnosing inflammatory causes of chronic diarrhoea. The American journal of gastroenterology 1998; 93 (8): 13001305.

27. Saunders BD, Trapp RG, eds. Basic and clinical biostatistics Connecticut: Appleton and Lange 1990.

28. Kosek M, Bern C, Guerrant RL. The global burden of diarrhoeal disease, as estimated from studies published between 1990 and 2005. Bull WHO 2003; 81 (3): 2-8.

29. Mukhtar AMP. Rotavirus antigen detection and bacteriological study of acute infantile and childhood diarrhoea. Ain-Shams International Medical Congress. 19th ed. Cairo (Egypt) 1996.

30. Bughdadi AA, Tadrus AM, Mansour $\mathrm{MB}$ and Nushi S. Giardiasis in a rural community in middle Egypt. The New Egyptian Journal of Medicine 1989; 3 (1): 133-41.

31. Nofal AAM. A study on the prevalence of shigellosis and acute amoebic dysentery among infants and children presenting with bloody diarrhoea. Thesis, MD. Alexandria: University of Alexandria, Faculty of Medicine 1996.
32. Torres ME, Pirez MC, Schelotto F, Varela G, Parodi V, Allende F, et al. Etiology of children,s diarrhoea in Montevideo, Urguay: Associated pathogens and unusual isolates. J Clin Microbiol 2001; 39(6):2134-9.

33. Jeanson A, Jamart J, Maisin JM, Vanheuverzwyn R, Gohy P, Debongnie JC, et al. Assessment of the new immunological test hemoblot for detecting occult blood in stool. J Cancer Prev 1994; 3(5): 407-12.

34. Mertens TE, Wijenayake R, Pinto MR, Peiris JS, Wijesundera MD, Eriyagama NB, et al. Microbiological agents associated with childhood diarrhoea in the dry zone of Srilanka. Trop Med Parasitol 1990; 41(1):11520.

35. Barnes GL, Uren E, Stevens KB, Bishop RF. Etiology of acute gastroenteritis in hospitalized children in Melbourne, Australia, from April 1980 to March 1993. J Clin Microbiol 1998; 36 (1): 133-8.

36. Kotloff KL, Wasserman SS, Steciak JY, Tall BD, Losonsky EA, Nair P, Morris JG Jr, et al. Acute diarrhoea in Baltimore children children attending an outpatient clinic. Pediatr Infect Dis J 1998; 7 (11): 753-9.

37. Abd El-Salam ShM. The polymerase chain reaction in detection and characterization of Campylobacter from human cases and environmental sources. Thesis, PHD. Alexandria: University of Alexandria, Faculty of Medicine 1996.

38. Albert MJ, Faruque ASG, Faruque SM, Sack RB, Mahalanabis D. Casecontrol study of enteropathogens associatedwith childhood diarrhoea in Dhaka, Bangladesh. J Clin Microbiol 1999; 37(11): 3458-64. 
39. Ahmetagic S, Jusufovic E, Petrovic J, Stojic V, Delibegovic Z. Acute infectious diarrhoea in children. Med Arch 2003; 57(2):87-92.

40. Khair Allah ZH, El Saadawi MM and Abdel Hady AA. Enteropathogenic microflora causing diarrhoea in children. Egyptian Journal of Microbiology 1998; 33(2):233-50.

41. Salah El Din NH. Detection of Ecoli O 157:H7 associated with hemorrhagic colitis in Egypt. Thesis, MD. Cairo: University of Cairo, Faculty of Medicine 1995.

42. El- Abhar EA. Evaluation of risk facors for life threatening acute diarrhoea in infancy and childhood. Thesis MD. Cairo: Al-Azhar University, Faculty of Medicine 1990.

43. Rezq NG. Enterotoxigenic E coli and pediatric diarrhoea. Thesis, MD. Alexandria; University of Alexandria, Faculty of Medicine 1993.

44. El-Dakhakhni MYS, Helal ESA and El-Dafrawi MS. Prevalence of Campylobacter spp. in infantile diarrhoea in Cairo. Egyptian $\mathrm{M}$ edical Journal 1990; 7(11)634-7.

45. Abu-Elyazeed R, Wierzba ThF, Mourad AS, Peruski LF, Kay BA, Rao $\mathrm{M}$, et al. Epidemiology of enterotoxigenic $E$ coli diarrhoea diarrhoea in a pediatric cohort in a periurban area of Lower Egypt. The Journal of Infectious Diseases 1999; 79:382-9.

46. Afifi ZEM, Nasser SS. Aetiology of childhood diarrhoea in an Egyptian rural community. Journal of Tropical Pediatrics 1996; 42(2):116.

47. Mikhail IA, Hymas KC, Podgore JK, Haberberger RL, Boghdadi AM, Mansour NS, et al. Microbiological and clinical study of acute diarrhoea in children in Aswan, Egypt. Scand $\mathrm{J}$ Infect Dis 1989; 21:59-65.
48. El Mourshedi H. Intestinal protozoal infection among diarrhoeic preschool children. Infection determinants and its impact on nutritional staus. Bulletin of High Institute of Public Health 1997;27(2):183-94.

49. Zytoon MA. Cryptosporidiosis in children with acute and persistent diarrhoea. Thesis, MD. Alexandria: University of Alexandria, Faculty of Medicine 1995.

50. Gabriel J, Pelaez R, Mattar S. Accuracy of faecal lactoferrin and other stool tests for diagnosis of invasive diarrhoea at a Colombian pediatric hospital. Pediatr Infect Dis J 1999; 18(4):342-6.

51. Bardhan PK, Beltinger J, Beltinger RW, Hossain A, Mahalanbis D. Screening of patients with acute infectious diarrhoea: evaluation of clinical features, faecal microscopy and faecal occult lood testing. Scand J Gastroenterol 2000; 35(1):54-60.

52. Fried K, Tarkanyl K, Prinz G, Ban E. Detection of lactoferrin in feaces for differential diagnosis in diarrhoea. Orv Hetil 2002; 143(37):2141-4.

53. Kane SV, Sandborn WJ, Rufo PA, Zholudev A, Boone J, Lyerly D, et al. faecal lactoferrin is a sensitive and specific marker in identifying intestinal inflammation. Am J Gastroenterol 2003; 98(6):1309-14.

54. Guerrant RL, Zaenker El, Choi SW and Park $\mathrm{ChH}$. Faecal lactoferrin screening assay for inflammatory bacterial diarrhoea. J Clin Microbiol 1996; 34(9):2338-41.

55. Nachamkin I. Letters to the editor. Faecal lactoferrin screening assay for inflammatory bacterial diarrhoea. J Clin Microbiol 1996; 34(9):2337-8.

56. Huicho L, Campos M, Rivera J, Guerrant RL. Faecal screening tests in the approach to acute infectious 
diarrhoea: a scientific overview. Pediatr Infect Dis J 1996; 15(6):48694.

57. Miller JR, Barrett LJ, Katloff K, Richard L, Guerrant RL. A rapid test for infectious and inflammatory enteritis. Arch Intern Med 1994; 154:2660-4.
58. Oberhelman RA, Guevero SE, Mercado D, Fernandez ML, Mera R. Observations on the impact of breastfeeding and of intestinal helminthiasis on a rapid agglutination assay for faecal lacoferrin in Nicaraguan children with diarrhoea. Pediatr Infect Dis J 1999;18 (10):944-6. 